\title{
A renda que enreda: Analisando o processo de constituir-se rendeira
}

\author{
Andréa Vieira Zanella* \\ Gabriela Balbinot** e \\ Renata Susan Pereira***
}

RESUMO: Este artigo apresenta a análise das transformações das significações sociais da atividade foco deste estudo - a renda de bilro - e suas implicações no processo de constituição de um sujeito aprendiz. As reflexões aqui apresentadas pautam-se nos pressupostos teóricos da Psicologia Histórico-Cultural. O resgate do contexto, isto é, da história do grupo em que este sujeito se insere, bem como da atividade em questão caracterizaram-se como importante aspecto do percurso traçado. Os dados analisados provêm de entrevistas realizadas com o sujeito. $O$ desenvolvimento das análises possibilitou concluir que a constituição do sujeito é um processo complexo, multifacetado e ininterrupto onde a participação dos outros sujeitos tem relevância significativa mas não determinante nas suas escoIhas, de maneira a singularizar algo que é socialmente partilhado.

Palavras-chave: Psicologia social, cultura, gênero, constituição do sujeito, (re)significação

Estudar o processo de constituição do sujeito através das significações produzidas e veiculadas é a tônica desta investigação a qual, continuando os estudos realizados por Zanella (1997), fundamenta-se na psicologia histórico-cultural, mais especificamente nos aportes teóricos de L. S. Vygotski e alguns de seus interlocutores ao longo das últimas décadas.

\footnotetext{
*Professora adjunta da Universidade Federal de Santa Catarina. UFSC. E-mail: azanella@cfh.ufsc.br

** Graduanda em Pedagogia na UFSC.

*** Graduanda em Pedagogia na UFSC.
} 
Considerando-se o sujeito como histórico e social, a investigação do processo de sua constituição pressupõe que este seja estudado numa atividade específica, posto que é via atividade mediada por instrumentos materiais e semióticos que o homem transforma o contexto no qual se insere ao mesmo tempo em que por este é modificado (Vygotsky, 1991b). Por sua vez, entendendo que o sujeito é constituído no campo da intersubjetividade ${ }^{1}$, nas relações concretas que estabelece, não há como analisar o seu discurso omitindo o contexto das relações sociais em que ele é produzido.

Com relação à atividade foco do presente estudo - a renda de bilro - trata-se de uma manifestação cultural e, como tal, deve ser entendida como atividade social realizada por uma determinada coletividade. Desse modo, ao aprendê-la o sujeito apropria-se não somente de um fazer, mas de toda a história e valores que o caracterizam, sendo que, ao mesmo tempo, imprime a estes sua marca singular.

Para a análise do movimento de constituir-se rendeira trabalhamos com um sujeito que, apesar de ter nascido no seio de um grupo rendeiro da Ilha de Santa Catarina, distancia-se da atividade e, mais tarde, procura reaproximar-se desta. Assim, matricula-se em uma oficina de renda de bilro e retoma, decorridos mais de quinze anos, a atividade de fazer renda.

A fonte de dados consistiu, inicialmente, nas entrevistas realizadas por Zanella (1997) com Nice - sujeito da atual pesquisa - e com a professora de renda de bilro, D. Judite. A análise desse material possibilitou a elaboração de um roteiro semi-estruturado para uma segunda etapa de entrevistas.

Considerando que existe "... um duplo referencial semântico nos processos de significação: um formado pelos sistemas de significação construídos ao longo da história social e cultural dos povos; outro formado pela experiência pessoal e social de cada indivíduo, evocada em cada ato discursivo" (Pino 1993, p. 21) aqui resgatamos, ainda que brevemente, tanto a história do grupo social em que o sujeito se encontra inserido, quanto sua história pessoal. Cabe destacar, porém, que não estamos pesquisando toda a história de vida de Nice, mas sim uma esfera reduzida dela - sua história com o aprender a tecer a renda de bilro, razão pela qual utilizamos, na coleta de dados, a técnica de trabalho com depoimentos (Queiróz 1988).

Desse modo, o que iremos aqui apresentar são fragmentos do discurso coletado, especificamente no que se refere ao ser rendeira e às transformações na significação desta atividade para o sujeito da pesquisa, transformações estas que precisam ser analisadas no contexto das re- 
lações e práticas sociais que as engendram. Assim sendo, para a investigação do objeto em questão procuramos, através da análise das múltiplas vozes presentes tanto na história da atividade quanto na história de Nice, tecer reflexões sobre o movimento de constituição do sujeito.

\section{Renda, rendeira, rendar: Um breve olhar sobre a história da renda de bilro na Ilha de Santa Catarina}

A origem da palavra renda não é bem conhecida. A renda é definida, por Bueno (1988), como lavor de agulhas ou ainda como tecido muito fino e aberto. Aparece também como dissimilação do espanhol randa, que veio do provençal randa - adorno, deverbal de randar, adornar. Já em Nascentes (1966), renda é uma palavra aparentada do espanhol e do catalão, de origem incerta, talvez céltica.

O significado da palavra renda aparece como "... tecido de malhas abertas e contextura geral delicada, cujos filos (de linho, algodão, seda, etc.) trabalhados à mão ou à máquina, entrelaçam-se formando desenhos e que é usado para guarnecer ou confeccionar peças de vestuário, alfaias, roupas, roupa de cama e mesa, etc." (Ferreira 1986, p. 1484)

Em relação à atividade que se constitui como nosso objeto de estudo, destaca-se que, para trabalhar essa renda, faz-se necessário a utilização de pequenas peças de madeira, os bilros. São assim chamados provavelmente (não se sabe ao certo) porque a madeira de que são feitos vem de uma árvore denominada bilreiro (Nascentes 1966). Também se considera uma origem latina para a palavra bilro - que viria de pirulus, diminutivo de pirus (pêra) -, pela semelhança com a forma de ambos os objetos, a fruta e o bilro (Bueno 1988). E, ainda, ao manusear os bilros com a notável destreza com que o fazem, as rendeiras (mulheres que trabaIham na renda) produzem um som resultante do "bater dos bilros" ${ }^{2}-$ que, para os poetas, tem ritmo e musicalidade semelhante aos estalidos que as "rendeiras" (aves da família Pipridae) fazem ao dançar (Nascentes 1966).

Essas características nos falam da renda em sentido genérico. Mas o que dizer dessa atividade no contexto aqui proposto?

A renda de bilro ou renda de almofada ${ }^{3}$, artesanato que veio para a Ilha de Santa Catarina na metade do século XVIII trazida pelos imigrantes açorianos, sempre foi confeccionada prioritariamente pelas mulheres 
e, nas primeiras décadas da imigração, seu uso restringia-se ao enfeitar casas e igrejas. Realizada no âmbito doméstico, a atividade de fazer renda era importante fator de constituição do feminino (Zanella 1997).

Encontra-se, no entanto, em Bueno (1988), tanto a definição de "rendeira" quanto de "rendeiro", ambos descritos como mulher/homem que faz e/ou vende renda. Para a comunidade onde Nice nasceu e cresceu, porém, a delimitação de espaços específicos para o feminino e o masculino era clara: a atividade rendeira ficava circunscrita à mulher, enquanto a pesca era praticada pelo homem (Beck et al. 1982).

Nice nos fala sobre a distância social entre homem/renda e como esta ainda hoje se mantém:

Algumas pessoas me disseram que alguns homens aprenderam a fazer renda... por exemplo, lá no Casarão ${ }^{4}$ a gente tem um vigia que já me falaram que ele sabia fazer renda, que ele aprendeu. Ele nunca admitiu... eu perguntei várias vezes, a gente trabalhava junto, tinha um relacionamento legal, assim, ele nunca admitiu, ele falava "Renda, renda não!" (risos), como se fosse só pra mulher. Então eu não sei se algumas pessoas sabem e não assumiram que sabem fazer...

A demarcação de territórios específicos para as atividades femininas e masculinas nesse contexto social, bem como as transformações decorrentes do processo de urbanização, é temática que vem sendo investigada por Lago (1996). À pesca, atividade masculina inscrita em um contexto público, contrapunha-se a renda, tecida pelas mulheres em círculos restritos. Desse modo, tanto o aprendizado quanto a confecção da renda consistiam, naquela época, em atividades desenvolvidas no âmbito doméstico. Com o advento do turismo, em meados deste século, esse artesanato passou a ser valorizado/destacado para além desse espaço. A renda começa assim a estabelecer-se no contexto econômico e a atividade é re-significada (Zanella 1997): de artesanato feito por entretenimento e que se constituía em instrumento regulador da conduta feminina, na medida em que mantinha a mulher em casa, passa a ser uma atividade geradora de mercadorias. A comercialização delas possibilitava-Ihes complementar a renda familiar e, em alguns casos, garantia sua independência financeira, situação vivenciada pela família de Nice: 
... a Norma ${ }^{5}$ na realidade é que era a dona da barraca ${ }^{6}$ junto com a minha mãe. Então a Norma teve toda uma história de renda, assim, eu lembro dela, ela comprou todo o enxoval dela com renda, ela sempre se sustentou da renda, ela, das nossas irmãs, era a mais independente financeiramente...

Essas transformações por que passou a renda de almofada acarretaram mudanças não só na estética das peças mas também no processo de ensinar/aprender a atividade. A simplificação da renda de bilro, via retirada de alguns pontos que prolongavam o tempo de confecção, facilitou a aprendizagem e a inserção precoce das jovens no mercado de trabalho, em geral com 6, 7 anos.

É possível compreender, com esses dados, que a mesma atividade cumpriu, em sua história, um duplo papel: se inicialmente mantinha a mulher no espaço doméstico, a sua valorização permitiu a essas mesmas mulheres o contato com o espaço público, ainda que de forma a garantir, via renda que gerava renda, a manutenção do primeiro. $O$ fato de nem sempre gerar renda, porém, associado às transformações sociais, econômicas e políticas da llha, aceleraram o processo de conquista, por parte das mulheres rendeiras, do espaço público, ainda que o preço para tanto venha sendo a extinção da atividade, no que se refere a seu aspecto econômico (Zanella, 1997).

A trajetória de Nice nos ajuda a compreender melhor esse movimento.

\section{Nice e a renda: primeiras aproximações}

A história de Nice com a atividade rendeira a diferencia do que foi vivido por suas irmãs: apesar de ter tido contato com o fazer renda muito cedo, logo distanciou-se dos bilros e almofadas.

Em razão das rápidas transformações no interior da llha de Santa Catarina decorrentes do turismo e conseqüente explosão imobiliária (Lago 1996), o contato com a urbanização engendrou um movimento acelerado de transformação dos valores e costumes locais. A trajetória de Nice nos permite vislumbrar o quanto essas mudanças refletiram em sua história, diferenciando-a de suas irmãs: a insistência para que ela aprendesse a fazer renda foi relativa e, com dez anos de idade, con- 
quistava o espaço da rua acompanhando o pai em suas andanças pelo bairro, vendendo leite de porta em porta.

Já adulta, no entanto, Nice volta a se aproximar da atividade, desta vez em outro contexto, em outra posição e motivada por interesses distintos. Esse movimento, visível em sua fala, permite identificar que, em relação ao fazer renda, sua história apresenta quatro momentos distintos, porém mutuamente complementares. $O$ primeiro deles refere-se ao contato inicial com a renda, por volta de 6, 7 anos, marcado em seu discurso pela curiosidade. Já o segundo momento refere-se à apropriação, por parte de Nice, do significado do lucro que a atividade era capaz de reverter àqueles que a ela se dedicavam; assim,

\begin{abstract}
Passando a curiosidade, claro que eu não queria ficar sentada numa almofada fazendo renda, né?(...) Mas depois veio uma história de que era gratificante tu tirar um trabalho da almofada e vender, isso era uma coisa que eu me lembro que era legal, e daí no começo eu fiz uma renda que era horrorosa, era um amarelo ouro (risos) e que alguém levou ${ }^{7}$, assim, nossa, eu fiquei super feliz!
\end{abstract}

O terceiro momento refere-se não mais à curiosidade de Nice em relação à atividade, mas em relação àqueles que se interessavam pelo fazer renda e pelo seu produto. Neste momento Nice registra em sua fala a chegada dos turistas, de pessoas que vinham de outros lugares, com costumes diferentes e que entravam, via renda, em seu universo cultural.

Enquanto num momento anterior a atividade de fazer renda era o novo, agora essa mesma atividade passava a se caracterizar como o meio de acesso/apropriação de um outro novo, de algo diferente. Ao vender a renda Nice vendia o produto da sua atividade e, concomitantemente, apropriava-se de uma nova forma de inserção social veiculada pelo turista.

E para as pessoas novas era pra gente muito curioso, era muito novo. Nós éramos muito caipiras (risos) para as pessoas, na realidade, imagina, ... o meu pai tinha uma vaca ali quase na beira da estrada, as pessoas tomavam leite em caneco, então isso para as pessoas era uma curiosidade e para nós essa coisa do novo, do carro, do modo de se vestir... e vender, era diferente... 
Esses três primeiros momentos referem-se à infância de Nice, à sua história de sujeito inserido em um grupo social específico em que a renda de bilro se entrelaçava a conceitos e condições outras, já pontuadas neste texto, que são de fundamental importância no processo de sua constituição. No entanto, a história desse sujeito é permeada pelas rápidas transformações do contexto em que se insere e principalmente pela leitura diferenciada que este faz da atividade em meio a esse processo. Nice, a renda e o contexto, todos em um movimento de constituição e diferenciação permanente, vão configurando uma história singular.

A Lagoa da Conceição se mantém enquanto espaço para o morar, porém outros espaços são conquistados pela "filha de rendeira": para continuar seus estudos Nice procura escolas no centro da cidade. A subsistência era obtida com a inserção no mercado de trabalho como assalariada, assumindo funções de secretária em consultórios particulares e posteriormente em órgãos da administração pública municipal. Paralelo ao trabalho, continuou os estudos e concluiu o curso universitário de biblioteconomia.

Tecidos outros rumos, escolhidas outras trajetórias, ela porém volta a se aproximar da renda, o que identificamos como o quarto dos momentos anteriormente referidos: sobre essa reaproximação e suas implicações é que iremos aqui nos deter.

\section{Nice reaprende a fazer renda}

Quando foi trabalhar no Casarão da Lagoa em meados de 1994, na condição de funcionária pública municipal de Florianópolis, Nice teve a oportunidade de resgatar sua própria história. Durante o tempo em que esteve ligada a esta entidade desenvolveu um projeto, juntamente com outra funcionária, denominado "A renda sob um novo olhar".

Nice estava formando o Acervo de Piques do Casarão (vide nota n. 3) e, para tanto, coletava os modelos de renda junto às rendeiras da Lagoa da Conceição e da Barra da Lagoa ${ }^{8}$. Essa coleta não era fácil por duas razões: pela dificuldade em obter os piques, pois as rendeiras muitas vezes negavam-se a emprestar os modelos antigos, receosas de que pudessem ser extraviados. Soma-se a isso o fato de que, por serem produzidos e reproduzidos de forma artesanal, com o passar dos anos e as 
sucessivas cópias, os piques apresentam pequenos defeitos - decorrentes da omissão de perfurações ou da mudança do ângulo das mesmas (Zanella 1997) - que comprometem sua utilização, bem como a qualidade da renda a ser confeccionada.

Ao coletar os piques Nice se deparou com esses problemas:

E daí eu comecei a ver que algumas coisas eu não entendia, algumas saídas prá bico ${ }^{9}$, entendeu? Onde, por que tinha aquele furo ali? Tinha umas coisas que não se encaixavam. Aí eu comecei a perceber que eu precisava de mais elementos na realidade para confeccionar os..., é claro que até hoje eu vou precisar, né... porque é uma coisa muito..., assim, que foi se modificando, foi se alterando a forma e o modelo de fazer.

A necessidade de compreender melhor como a renda era tecida, necessidade esta relacionada ao seu trabalho, foi o que impulsionou Nice a matricular-se na Oficina de Renda. Porém, embora a busca pela atividade tenha partido destas circunstâncias, Nice logo se interessou pela idéia de confeccionar suas próprias peças:

... eu queria saber se eu conseguia fazer um trabalho maior, naquela coisa que tu tem a imagem que as tuas irmãs faziam...

A retomada da atividade, o deleite de se ver tecendo pontos por ela há muito já conhecidos e esquecidos, o desejo de inovar e personalizar suas peças, desencadeia em Nice um interesse que não havia despertado quando criança: o de se reconhecer e de ser reconhecida enquanto rendeira. A atividade de coletar os piques tem, nesse sentido, uma importância crucial: possibilita estar novamente em contato com aspectos de sua própria história, reaproximando-a tanto de pessoas quanto de suas trajetórias. Desse modo, ao procurar os piques, Nice resgata não só os trabalhos em renda, mas fundamentalmente o percurso histórico de uma determinada manifestação cultural, com as significações que lhe são atribuídas.

Porém, o retorno à renda marca e é marcado pela sua história de vida. Os olhares outros que desenvolveu em sua trajetória singular fazem com que o seu aprendizado, na confecção da renda de bilro, seja pau- 
tado tanto pelo resgate do tecer tradicional, tal como vem sendo feito pelas mulheres de sua família, quanto pela necessidade de inovar:

...foi aquela coisa de querer fazer, querer criar coisas novas (risos), porque eu sempre tive essa coisa assim da renda sob um novo olhar, né!

A frase acima nos permite compreender que o significado do aprender a fazer renda para Nice atende a muito mais que uma necessidade profissional: para além do resgate e cadastro dos antigos modelos, o seu interesse consiste em "criar", em produzir novas rendas. Do contrário, seu retorno ao rendar teria se esgotado assim que tivesse alcançado seu objetivo inicial, o aprender a fazer renda para compreender os piques.

O criar novas rendas, por sua vez, parece estar vinculado a uma preocupação de Nice que se sustenta nos fatos observados em relação à atividade de confecção da renda de bilro: assim como ela, outras tantas filhas e netas de rendeiras deixaram a atividade de lado. Enquanto manifestação cultural caracterizada como artesanato, porém, a sobrevivência da renda de bilro depende fundamentalmente do interesse de pessoas em aprender a tecer e ensinar a outros que continuem esse mesmo movimento.

No decorrer de seus depoimentos, Nice expressa que o aprender a fazer renda não é suficiente para a sobrevivência da renda de bilro o que se é possível apreender via diferenciação entre o "saber fazer renda" e o "ser rendeira". Sua crítica relaciona-se ao fato de que muitas pessoas procuram as aulas de renda por mera curiosidade, dedicando-se à atividade por um período de tempo muito curto.

Elas aprenderam para saber como que é, tipo experimentar: "Vou experimentar uma aula disso, vou experimentar uma aula daquilo..." "Eu ouvi falar..." uma coisa de conhecimento geral, né?... Então, isso eu não sei se eu consigo considerar hoje como uma pessoa que é rendeira. Eu acho que daqui a alguns anos é isso que tu vai poder considerar nas pessoas, elas sabem fazer ou não sabem fazer. Sabe fazer, senta, faz uma perna cheia ${ }^{10}$, faz nãosei-o-quê, e é isso que vai nos restar. Não vai ter essa continuação de história de... porque essa coisa é só pra não se perder o ponto, né?, mas as rendas vão ser perdidas, as pessoas não vão 
ter elem... sabe?, elementos suficientes pra fazer uma renda tradicional e um novo, entende? No caso, vai faltar a história.

A preocupação de Nice refere-se à perda, por parte daqueles que são hoje em dia iniciados no fazer renda, do significado atribuído por ela ao "comprometer-se com a atividade". Isto quer dizer a continuidade da história tradicional, que não se consolida somente no produto, mas fundamentalmente no envolvimento afetivo e na possibilidade de criação que personaliza os trabalhos. Para ela, o fato de algumas pessoas se interessarem em aprender os pontos ou algumas peças não é suficiente para a sobrevivência da renda de bilro.

\section{Re-significando a renda e o rer rendeira: o movimento de Nice}

Falar em sujeito implica considerar para esse conceito a sua dupla acepção: a que se refere ao ser sujeito, à possibilidade de fazer opções imprimindo sua marca no contexto ao qual se insere, e ao fato de concomitantemente ser sujeitado ao contexto que o constitui. Essa dupla dimensão expressa tanto a complexidade do que se investiga - o sujeito - quanto dos caminhos trilhados para estudá-lo. Como resultado, observa-se com freqüência leituras que cindem sujeito/sociedade, objetivo/ subjetivo, singular/social, imputando valor maior ora para um lado, ora para o outro, perdendo com essa fragmentação a dialeticidade do processo em que "... um não é sem o outro, mas cada um se constitui pelo outro, sem se diluir nele" (Neves 1997, p.218).

Destaca-se assim a dimensão inextrincavelmente social do que se caracteriza como singular. Ou seja: não há um eu enquanto entidade metafísica, pois este só é a partir do outro, do que o constitui e que é por ele constituído. Mais ainda: só me reconheço enquanto eu a partir de outros eus, embate esse que é constante, posto que a diferença e diversidade pautam o humano. Porém, o embate se configura na medida em que reconheço esse não-eu e o significo de algum modo, seja rechaçando, ignorando, aproximando ou identificando-me com ele, em um movimento que vincula o não-eu ao eu e o eu ao não-eu.

A condição social do sujeito é explicada pelos aportes vigotskianos que destacam a consciência como semioticamente mediada (Vygotsky 
1991b). Em nossa cultura, ganham destaque como mediadores da consciência os signos lingüísticos, mais especificamente a palavra que veicula significados e sentidos. Esta, por sua vez, é sempre e necessariamente plural, como nos esclarece Bakhtin ${ }^{11}$ :

Na realidade, toda palavra comporta duas faces. Ela é determinada tanto pelo fato de que procede de alguém, como pelo fato de que se dirige para alguém. Ela constitui justamente o produto da interação do locutor e do ouvinte. Toda palavra serve de expressão a um em relação ao outro. Através da palavra, defino-me em relação ao outro, isto é, em última análise, em relação à coletividade. A palavra é uma espécie de ponte lançada entre mim e os outros. Se ela se apóia sobre mim numa extremidade, na outra apóia-se sobre o meu interlocutor. A palavra é o território comum do locutor e do interlocutor (1990, p. 113)

Compreender o eu, portanto, é tarefa árdua e somente possível no contexto da trama em que o sujeito tece e é tecido, onde as significações são produzidas, apropriadas e veiculadas. Certas das dificuldades a serem enfrentadas e dos nossos próprios limites, atrevemo-nos aqui a "ad-mirar" o movimento de Nice em relação ao fazer renda, movimento este que expressa concomitantemente o embate produzido pelas vozes em questão e as transformações engendradas nas significações do "ser rendeira". Vejamos.

O retorno de Nice ao fazer renda de bilro atendeu, à primeira vista, a necessidades profissionais, pois resgatar os modelos antigos de renda demandava conhecimentos específicos sobre a atividade que a permitissem corrigir traçados, entender signos aparentemente desconexos para leitores que desconhecem a linguagem veiculada. Esse resgate, porém, confrontoua com uma realidade que, se em princípio não lhe era desconhecida, passou a ser objeto de interesse e reflexão: a estagnação da atividade e a perspectiva de sua extinção. Desse embate resulta, como ela mesma diz, o movimento de "pensar a renda sob um novo olhar". Essa inquietude e a não conformidade com o que está posto marca tanto o seu olhar quanto o produto do seu tecer, o que dá à sua renda uma característica viva, de movimento constante. Como esse novo olhar se materializa?

Reclamando do excesso de porta-bandejas ${ }^{12}$ que vê nas barracas, Nice contrapõe-se a isso, confeccionando prioritariamente peças para se- 
rem utilizadas como vestuário, modificando assim uma prática comum de confecção de renda para decoração de residências. Essa mudança é justificada, também, pelo fato de querer que um número maior de pessoas tenha contato direto com esse artesanato. O confeccionar peças de vestuário caracteriza-se, desse modo, como estratégia sua para divulgar a renda de bilro e despertar o interesse da comunidade em aprender a tecê-la.

Outras diferenças caracterizam a re-aproximação de Nice em relação à atividade: a renda divide espaço com a profissão e os estudos, tornando assim sua dedicação ao confeccionar limitada. Em decorrência, não se observa a agilidade no manuseio dos bilros, característica que identifica culturalmente as rendeiras da Ilha de Santa Catarina e é considerada por essas como requisito para serem assim reconhecidas:

\begin{abstract}
... nitidamente tu vai me ver passando os bilros e tu vai conseguir até entender como se passa. Algumas pessoas conseguem entender e falam "- Nossa, você faz tão devagar que eu consigo aprender!" Então, nesse sentido eu nunca vou ser considerada uma rendeira, porque isso também não é o meu propósito, né... até gostaria de alcançar isso, mas assim não nesse sentido de ser uma rendeira, mas no sentido que eu acho legal ter toda aquela maleabilidade rápida...
\end{abstract}

Nice sabe que a agilidade com os bilros é um requisito cultural, social e historicamente produzido pelas mulheres que tecem a renda e aceito pelo grupo social em que se inserem, o qual as identifica como rendeiras genuínas. Reconhece também que, com esse parâmetro e dadas as suas condições em relação à atividade (contato esporádico, tempo parcial de dedicação aos bilros e almofada), ela não será reconhecida como rendeira, o que em princípio afirma não ser o seu propósito.

Tem-se aqui um paradoxo. Apesar de saber fazer renda, de ser descendente direta de rendeiras tradicionais e viver cercada por mulheres que desenvolvem a atividade, Nice não é identificada como tal. No entanto, cabe perguntar: poderia ela ser considerada rendeira pelo fato de saber fazer renda e ter nascido no seio de uma família rendeira? Bastariam essas condições para que fosse reconhecida e se sentisse pertencente a tal coletividade específica? Nice é rendeira? Alguém a reconhece como tal?

Responder a essas perguntas demanda retomar aspectos do que é considerado característico desse grupo social e que o identifica, destacan- 
do-se aí o saber fazer renda de bilro. Quanto a Nice, antes de voltar a aprender a confeccionar a renda, não poderia ser reconhecida como rendeira por não deter o saber compatível com esse lugar social. No entanto, a questão aqui levantada se complexifica: mesmo depois de aprender a confeccionar a renda de bilro e conseguir tecê-la com independência, demonstrando pleno domínio dos instrumentos necessários e imprimindo a sua marca singular no que produz (o que se materializa nas inovações propostas), enfim, mesmo com a apropriação da atividade (vide Zanella 1997), com tudo isso ou apesar disso Nice não é identificada como integrante deste grupo: “...na minha família ninguém me considera rendeira".

Ao excluírem o sujeito que se diferencia - Nice - do seu grupo de referência, as vozes que o cercam parecem empreender um duplo movimento: preservam uma tradição - e, portanto, o que as identifica - e, ao mesmo tempo, demarcam um lugar para o que se aproxima de sua marca, porém com outras características. A esse outro, ao diferente, imputam o lugar do "não rendeira", do "saber fazer renda porém não como a fazem", o de quem produz renda mas não a renda que conhecem e caracteriza a sua história e trajetória.

O movimento que empreendem no sentido de demarcar um lugar social específico para si mesmas, elegendo signos de identificação como a agilidade no manuseio dos bilros, caracteriza o processo de preservação e inclusão que, por sua vez, pressupõe, inexoravelmente, a exclusão de quem não compartilha esses mesmos signos. Quem é excluído? No caso em questão, Nice!

Mas qual o seu movimento em relação a isso? Produzir a exclusão, demarcar o próprio lugar identificando o que o compõe e o diferencia, é apenas parte do processo: necessário se faz saber o que esse outro, supostamente excluído, significa do que vivencia, como e o que escuta dessas vozes. A análise da fala acima apresentada nos dá pistas para responder a essa questão, mais especificamente quando diz que "...nesse sentido eu nunca vou ser considerada uma rendeira, porque isso também não é o meu propósito".

Para o sujeito investigado, a questão da agilidade no manuseio dos instrumentos mediadores da atividade não se faz relevante, pois elege outros critérios como necessários para ser identificado como integrante do grupo social "Rendeiras da Ilha de Santa Catarina". Assim como imprime à atividade sua marca via confecção de peças incomuns, Nice tece "um novo olhar" sobre o "ser rendeira": 
... Eu me considero rendeira, numa outra visão (...) Ser rendeira para mim (...) é saber tecer, essa coisa do tecer é ter uma visão geral dos pontos (...) tem uma coisa de sentimento, (...) ser rendeira prá mim é isso, é tu aprender a tecer e tu ter essa história, esse continuar na história.

Assim como a história da atividade passa por transformações, o processo de significação do "ser rendeira", apresentado pelo sujeito, acompanha esse movimento. Desse modo, a significação historicamente produzida e socialmente apropriada do ser rendeira é, face às mudanças no contexto em que se insere e as características singulares que imprime ao fazer renda, re-significada por Nice: ela modifica um significado que era até então mantido, posto que este não mais serve à nova dinâmica de relações e práticas sociais que caracterizam o contexto no qual se insere. Se "ser rendeira" significa "saber tecer com agilidade os modelos tradicionais de renda", mantendo-se esse significado, Nice não é rendeira. Porém, o que faz? Imprime novos sentidos, elege signos outros para definir o que é ser uma rendeira no contexto atual.

Assim, sentidos e significados mudam com o manusear dos bilros de Nice em seu que-fazer na renda. Pensando em seu projeto "A renda sob um novo olhar", agora não mais ela o faz em termos de unicamente rendar sua casa, mas faz da renda metáfora para outros espaços de sua vida: adornar o corpo ${ }^{13}$ e criar, mudando as cores e trabalhando com fios reciclados ${ }^{14}$. Isso a possibilita re-significar tanto o que pensa de si em relação à renda quanto à renda em si; pintar a história de seu grupo com novas cores, novos olhares e se utilizar da tradição para lhe agregar novas práticas culturais.

... eu me propus a trabalhar com cor, que na renda se trabalha com cores (...) neutras (...) me propus a trabalhar numa coisa de reciclagem de fio, tanto que todos os patuás que eu fiz, eles são todos muito emendados, são cheios de nós mesmo, e isso é uma .... não é uma coisa que foi porque emendou porque terminou a linha, foi intencional, foi uma coisa de que eu estava a fim que isso acontecesse, a reutilização dos fios.

Esta fala de Nice permite também apontar a questão de que em seu movimento de re-significar a atividade e seus sujeitos, entende que para ser 
rendeira não basta a habilidade técnica, mas que devem existir motivos outros, conforme já apontado: o afeto. E o que vem a ser isso? Pela continuação de sua fala podemos entender que "sentimento" é o seu compromisso com a história, tanto pessoal (da Nice que resgata a renda), quanto das mulheres descendentes dos imigrantes açorianos que, fazendo renda, preservam uma atividade secular que as identifica. Ser renderia consiste, assim, dadas as transformações que vêm re-organizando o viver dessas mulheres nesse contexto social específico, em "saber tecer, envolver-se afetivamente com a atividade e comprometer-se com a sua história".

O movimento empreendido por Nice, portanto, parece retratar tanto o seu processo de se constituir rendeira quanto os caminhos que a atividade vêm/pode vir a tomar. Com isso, deixa clara sua participação na história da renda, na medida em que reconhece características produzidas pelo processo histórico e social da atividade e imprime nesse mesmo processo a sua marca pessoal. Assim como Nice se apropria da cultura em que se encontra inserida, ela a personaliza.

Esse movimento propicia entender um pouco daquilo que realiza no/pelo grupo rendeiro: ao dialogar com as tradições, mais do que tecer o embate entre o já posto e o "novo" que produz, na verdade Nice tece uma conversa com os muitos outros com os quais se relaciona, re-significando o âmbito que a atividade de rendar ocupa naquele espaço cultural. O que se destaca nesse percurso é o processo que o "não-eu" não ser rendeira - impulsionou: após o distanciamento da atividade, a conquista de outros lugares sociais, a delimitação de territórios simbólicos outros, Nice desenvolveu um "olhar estrangeiro"15 que a permitiu reaproximar-se de sua própria história e, deliberadamente, assumir os bilros com que tece a sua trama. Nesse processo, no encontro/confronto com as significações que a circundam, estas são modificadas: ser rendeira implica o domínio dos instrumentos, mas não mais a velocidade com os bilros; o fazer renda, porém não (ou não somente) o que está posto. O compromisso com a atividade e sua história, por sua vez, é fundamental para que esta continue a existir, ainda que transformada.

O que a trajetória de Nice aqui apresentada nos mostra, ainda que analisada a partir de olhares específicos e marcados por trajetórias igualmente singulares, é o movimento em que o trançar fios de significados produzem novas rendas, onde o sujeito que tece é tecido pela trama da história de que faz parte/participa. Esperamos ter contribuído para a compreensão desse processo, ainda que tenhamos acompanhado somente um dos muitos fios que o compõe. 


\section{Notas}

1. Intersubjetividade é aqui entendida como “... lugar do encontro, do confronto e da negociação dos mundos de significação privados (ou seja, de cada interlocutor) à procura de um espaço comum de entendimento e produção de sentido, mundo público de significação." (Pino 1993, p. 22)

2. O "bater dos bilros" é importante no tecer a renda porque possibilita que os pontos fiquem firmes.

3. A renda de bilro na llha de Santa Catarina é confeccionada com fios de algodão enrolados nas extremidades dos bilros que vão sendo trançados de modo a formar desenhos. Tem-se também, como instrumentos mediadores da atividade, o pique (papelão furado e algumas vezes desenhado com a forma da renda a ser produzida), uma almofada (na qual se anexa o pique) e alfinetes para pregar os pontos.

4. Casarão da Lagoa: funciona como uma casa de cultura e é o espaço em que Nice trabalhava e onde também fez aulas de renda de bilro.

5. Irmã mais velha de Nice.

6. As rendas eram, e ainda são, vendidas em barracas montadas ao longo da Avenida das Rendeiras, situada no bairro da Lagoa da Conceição, onde o fluxo de turistas é bastante intenso. Juntamente com outras localidades da Ilha de Santa Catarina, os antigos habitantes da Lagoa procuram preservar as tradições dos imigrantes açorianos como a renda de bilro, a festa do Divino Espírito Santo e a Farra do Boi.

7. Nice refere-se ao fato de ter conseguido vender a sua renda.

8. Bairros situados na região leste da Ilha de Santa Catarina que ainda hoje se mantém como referência de localidades em que aspectos da cultura açoriana são preservados.

9. Bico é uma das partes em que se divide o bordado da renda. Geralmente consiste em uma barra de detalhes que circunda o centro do trabalho, formando figuras que ora parecem com conchas, ora com pétalas de flores ou outros.

10. Juntamente com a trancinha e o meio ponto, a perna cheia consiste em um dos pontos básicos da renda de bilro.

11. A partir do resgate das contribuições do psicólogo francês F. Paulhan, Vigotski (1991a, p. 333) destaca que "...o sentido da palavra é a soma de todos os sucessos psicológicos evocados em nossa consciência graças à palavra. O significado é só uma dessas zonas do sentido, a mais estável, coerente e precisa".

12. Uma das peças mais produzidas pelas rendeiras.

13. Com bolsas, cintos, saias, tops e porta-patuás. 
14. Nice procura aproveitar fios de várias cores e espessuras diferentes produzindo, com isso, rendas em que vários nós aparecem.

15. Ao falar sobre o "olhar do estrangeiro", Peixoto (1988, p. 362) assim o define: "aquele que não é do lugar, que acabou de chegar, é capaz de ver aquilo que os que lá estão não podem mais perceber". Outra das possibilidades destacadas pelo autor e que melhor se aplica à situação de Nice observamos na passagem seguinte: "Uma das encarnações mais recorrentes do estranho, do recém chegado, é aquele que retorna."

Encaminhado para publicação em maio de 2000

The lace that net:

Analizing the process of being a lace embroiderer

ABSTRACT: This article presents an analysis of the transformations of the social significations of a handicraft activity, the bobbin-lace, and its implications in the process of constitution of a learner subject. The reflexions here presented rely on the theoretical principles of the sociocultural psychology. The recovering of the context, that means, the history of the group in which the subject takes place, as well as the history of the activity itself were important aspects of the path followed. The analysed data come from enterviews held with the subject. The development of the analysis made it possible to conclude that the constitution of the subject is a complex, multisized and permanent process in which the participation of the others does have a significative relevance but does not play a determinant role over the subject's choices, what allows him/her to turn something socially shared into a singular feature.

\section{Bibliografia}

BAKHTIN, M. Marxismo e filosofia da linguagem. 8 ed. São Paulo: Hucitec, 1990.

BECK, A.; COSTA, C.M.; TORRENS, J.C.; LACERDA, E.P. Roça, pesca, renda: trabalho feminino e reprodução familiar. Boletim de Ciências Sociais, no 23. Florianópolis: Ed. da UFSC, 1982.

BUENO, F. S. Grande Dicionário Etimológico-Prosódico da Língua Portuguesa. São Paulo: Lisa, vol. 7, 1988. 
FERREIRA, A. B. de H. Novo Dicionário da Língua Portuguesa. $2^{\mathrm{a}}$ ed.(rev. e aum.) Rio de Janeiro: Nova Fronteira, p. 1 484, 1986.

LAGO, M. C. de S. Modos de vida e identidade: sujeitos no processo de urbanização da Ilha de Santa Catarina. Florianópolis: Editora da UFSC, 1996.

MORIN, E. "A noção de sujeito", In: SCHNITMAN, Dora Fried (org.). Novos paradigmas, cultura e subjetividade. Porto Alegre: Artes Médicas, 1996.

NASCENTES, A. Dicionário Etimológico Resumido. [s.I.] Instituto Nacional do Livro, 1966.

NEVES, W.M.J. As formas de significação como mediação da consciência: um estudo sobre o movimento da consciência de um grupo de professores. Tese (Doutorado em Psicologia Social). PUC-SP.

PEIXOTO, N.B. "O olhar do estrangeiro", In: NOVAES, Adauto (org.). O Olhar. São Paulo: Companhia das Letras, 1988.

PINO, A. "Processos de significação e constituição do sujeito". Temas em Psicologia, ํㅜ 1, 1993.

QUEIRÓZ, M. I. P. de. "Relatos orais: do 'indizível ao' ‘disível’”. In: SIMSON, Olga de Moraes (org). Experimentos com histórias de vida: ItáliaBrasil. São Paulo: Vértice, 1988, p. 14-43.

VYGOTSKY, L.S. Obras Escogidas II: problemas de psicología general. Madrid: Visor Distribuiciones S.A., 1991a.

. Obras Escogidas III: problemas del desarollo de la psique. Madrid: Visor Distribuiciones S.A., 1991b.

ZANELLA, A. V. O ensinar e o aprender a fazer renda: estudo sobre a apropriação da atividade na perspectiva histórico-cultural. São Paulo. Tese de Doutorado em Psicologia da Educação - apresentada à Pontifícia Universidade Católica de São Paulo, 1997. 